\author{
V.A.Plotnikov, Yu.V.Katrashova
}

\section{THE "SMART CITY" CONCEPT: PRO- SPECTS FOR DEVELOPMENT AND THREATS TO IMPLEMENTATION (CASE OF ST. PETERSBURG)}

This paper presents the main characteristics of the concept of "smart city", based on the current trends of digital transformation of various spheres of activity of society and the state. Based on fundamental research in the field of digital technologies, as well as on the experience of implementing the "smart city" strategy of foreign countries, the analysis of the validity of methods for developing strategic plans for improving the city and its infrastructure facilities using ICT is presented. The risks and benefits of digitalization of the infrastructure of the city of St. Petersburg were also assessed. The main directions of the development of information and communication technologies, as well as digital technologies, providing integration and a plan for the effective implementation of the smart metropolis strategy are identified.

Keywords: information and communication technologies, ICT, digital technologies, digitalization, smart city, city transformation.

\section{В.А. Плотников ${ }^{1}$, Ю.В.Катрашова ${ }^{2}$ \\ ПЕРСПЕКТИВЫ РАЗВИТИЯ И УГРОЗЫ РЕАЛИЗАЦИИ КОНЦЕПЦИИ "УМНЫЙ ГО- РОД" (НА ПРИМЕРЕ САНКТ- ПЕТЕРБУРГА)}

В данной работе представлены основные характеристики концепции "умного города", базирующейся на современных тенденциях цифровой трансформации различных сфер деятельности общества и государства.

Опираясь на фундаментальные исследования в области цифровых технологий, а также на опыт внедрения стратегии "умного города" зарубежных стран, приведён анализ обоснованности методов развития стратегических планов по усовершенствованию города, его инфрраструктурных объектов с применением ИКТ. Также произведена оценка рисков и преимуществ цифровизации инфрраструктуры города СанктПетербург. Выявлены основные направления развития информационно-

коммуникационных, а также цифровых технологий, обеспечивающих интеграцию и план эффективной реализации стратегии умного мегаполиса.

Ключевые слова: информационнокоммуникационные технологии, ИКТ, цифрровые технологии, цифровизация, умный город, трансформация города.

\title{
Введение
}

В настоящее время отчётливо наблюдается рост урбанизации - население активно мигрирует из сельских поселений в городские, стремясь к более комфортным условиям жизни и широким возможностям реализации своих возможностей. Так, по состоянию на 1 января 2020 г. доля горожан в общей численности населения России составляла 74,7 \% (см.: https://showdata.gks.ru/report/278932) и имела тенденцию к росту. Однако, современные города, в особенности крупные мегаполисы, сталкиваются с многими проблемами, среди которых длинные автомобильные пробки, высокая загруженность общественного транспорта, значительный уровень содержания вредных веществ в атмосфере, недостаточное количество зелёных насаждений и др. Кроме того, во многих городах наблюдается дефицит городской инфраструктуры и диспропорции пространственного развития как следствие нерационального планирования инфраструктурных объектов и недостаточно чёткого надзора за реализацией имеющихся планов.

\footnotetext{
1 Плотников В.А., профессор кафедры общей экономической теории и истории экономической мысли, доктор экономических наук, профессор; Федеральное государственное бюджетное образовательное учреждение высшего образования "Санкт-Петербургский государственный экономический университет", г. Санкт-Петербург

Plotnikov V.A., Professor of the Department of General Economic Theory and History of Economic Thought, Doctor of Economics, Professor; Federal State Budgetary Educational Institution of Higher Education "Saint-Petersburg State University of Economics", Saint-Petersburg

${ }^{2}$ Катрашова Ю.В., контент-менеджер, Российская ассоциация спортивных сооружений, г. Санкт-Петербург

Katrashova Yu.V., Content Manager, Russian Association of Sports Facilities, Saint-Petersburg

E-mail: ul.katrashova@gmail.com
} 
Тенденция активной урбанизации влечёт за собой необходимость в грамотном управлении инфраструктурой города, основанном на инновационных методах и средствах достижения целей и решения задач, входящих в проекты по планомерному развитию города. В последнее время, благодаря быстрому развитию и проникновению цифровых технологий (в том числе и в сфере государственного управления [1]), особую актуальность приобретает так называемая концепция "умного города", призванная создать максимально комфортные условия проживания и обеспечить высокий уровень техногенной и экологической безопасности, основываясь на внедрении цифровых технологий в систему управления городом [2], [3], [4]. Переход к "умному городу" влечёт за собой цифровую трансформацию системы городского управления [5], [6].

Дополнительным стимулом к внедрению концепции "умного города" является пандемия COVID-19, которая стала триггером к переходу к цифровым форматам взаимодействия в ряде сфер общественных отношений (дистанционная занятость, обучение в удалённом интерактивном режиме, заказы товаров по интернету и т.д. [7], [8], [9], [10]) и увеличила потребность общества в обеспечении своей безопасности (в том числе и путём использования цифровых инструментов контроля). Эти тенденции соответствуют формату "умного города", вписываются в его концепцию, что подчёркивает актуальность и востребованность соответствующих преобразований.

Цель данной статьи заключается в описании, на основе анализа литературы, основных отличительных признаков "умного города", выявлении преимуществ и недостатков использования концепции "умного города" в городском управлении и оценке целесообразности внедрения этой концепции в России на примере Санкт-Петербурга.

\section{Основные характеристики концепции "умного города"}

Система умного города подразумевает собой целостную взаимосвязь информационно-коммуникационных технологий с интернетом вещей (IoT). Технология ІоТ опирается на совокупность датчиков с каналами передачи данных и центрами их обработки и хранения. Посредством ИКТ городское управление взаимодействует с обществом, следит за развитием и использованием инфраструктуры города, производит оценку средств улучшения качества жизни и решает множество других задач [11], [12]. Также ИКТ используются для повышения качества, производительности и интерактивности городских служб, снижения издержек и потребления ресурсов [13].

Современная модель умного города предполагает не только внедрение инновационных технологических решений, но и активное вовлечение жителей и бизнеса в их использование и развитие [14]. Стратегия умного города направлена на развитие умной инфраструктуры, упрощающей управление городскими процессами. Согласно данным Минстроя России, основными компонентами концепции умного города являются умное ЖКХ, умный городской транспорт, интеллектуальные системы ЭКО (онлайн-мониторинг атмосферного воздуха и воды), инфраструктура сетей связи и т.д. (более подробно эта информация приведена на Рис. 1).

Исходя из целей умного города, ориентированных на повышение качества жизни граждан, вытекают определённые задачи, позволяющие добиться эффективности реализации этой инновационной концепции на практике. Основными задачами умного города являются мониторинг и обеспечение актуальными сведениями в реальном масштабе времени сотрудников руководящих структур [15], создание и поддержание обратной связи между органами управления городом и его жителями, а также соблюдение порядка в городе. 


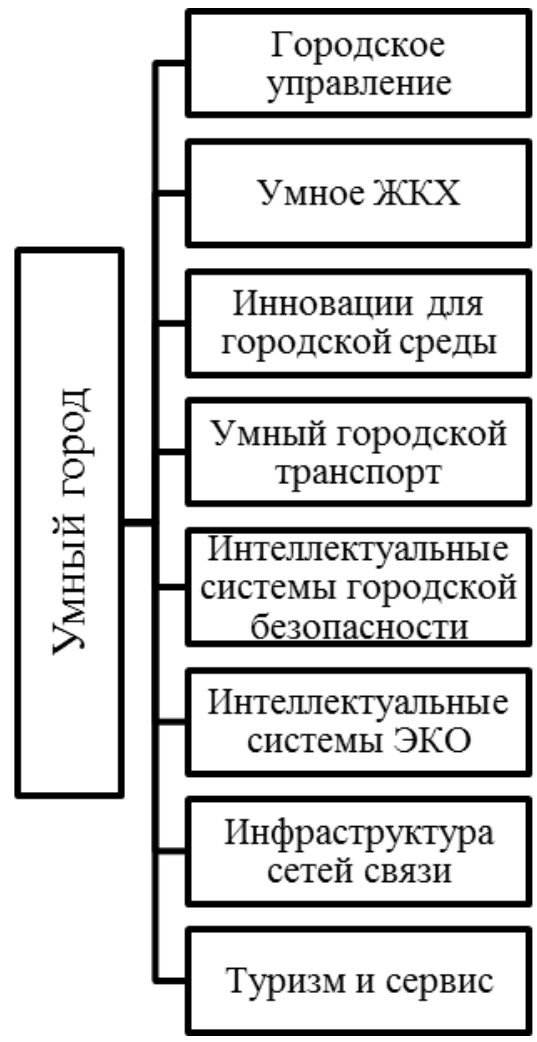

Рис. 1 - Компоненты стандарта "умного города" (по данным Минстроя России)

Для решения данных задач в систему умного города необходимо интегрировать датчики для осуществления непрерывного сбора необходимых данных от населения и специальных электронных встроенных приспособлений и организовать единую службу обратной связи [16], [17]. Полученная с их помощью информация является основой для принятия управленческих решений. Кроме того, особое значение имеют цифровые технологии. К примеру, геоинформационные технологии и сверхточная навигация совместно с сетями связи 5G являются предпосылкой для появления беспилотного общественного транспорта. Цифровые технологии поддержки принятия решений и обработки неструктурированных данных, машинное обучение необходимы для создания умных систем управления дорожно-транспортной инфраструктурой, включающей прогнозирование трафика, умные светофроры и даже контроль усталости водителей городских автобусов.

Таким образом, можно выделить главные элементы концепции умных городов, формирующие их технологическую инфраструктуру [18]:

- $\quad$ камеры видеонаблюдения и фотофиксации;

- $\quad$ современные транспортные развязки;

- основная система вызова экстренных служб;

- $\quad$ единая диспетчерская служба;

- $\quad$ интернет вещей;

- $\quad$ мобильная связь поколения $5 \mathrm{G}$.

Данные системы сбора и анализа данных помогают совершенствовать работу транспортной сети [19], повышать качество оказываемых медицинских услуг, увеличивать масштабы производства и остальных отраслей, создающих материальный базис интеллектуального города. Ядро интеллектуальной системы города - это информационнокоммуникационные технологии (включая цифровые), фрормирующие цифровой образ (аватар) города, который представляет собой совокупность актуальных знаний о состоянии объектов городской инфраструктуры и связей между ними. Среди главных составляющих частей процесса оцифровки города целесообразно выделить три этапа: оцифровка городской среды, оцифровка городских жителей и оцифровка связей их взаимодействия с объектами инфраструктуры [20], [21].

Цифровой образ городской среды предполагает набор качественных и количественных данных, характеризующих городские объекты [22]. На основе собранной инфрормации производится анализ состояния городской среды, и составляются прогнозы на 
краткосрочную или долгосрочную перспективу в зависимости от поставленных целей и методов сбора данных.

Цифровой образ горожанина (цифровой двойник) - параметрическая модель человека, описывающая его потребности и нужды, а также тип поведения. Целью построения такой модели является количественное представление и имитационное моделирование возможностей городской среды удовлетворить потребности жителя.

Исходя из вышесказанного, мы можем выделить основные особенности умного города, как это указано на Рис. 2.

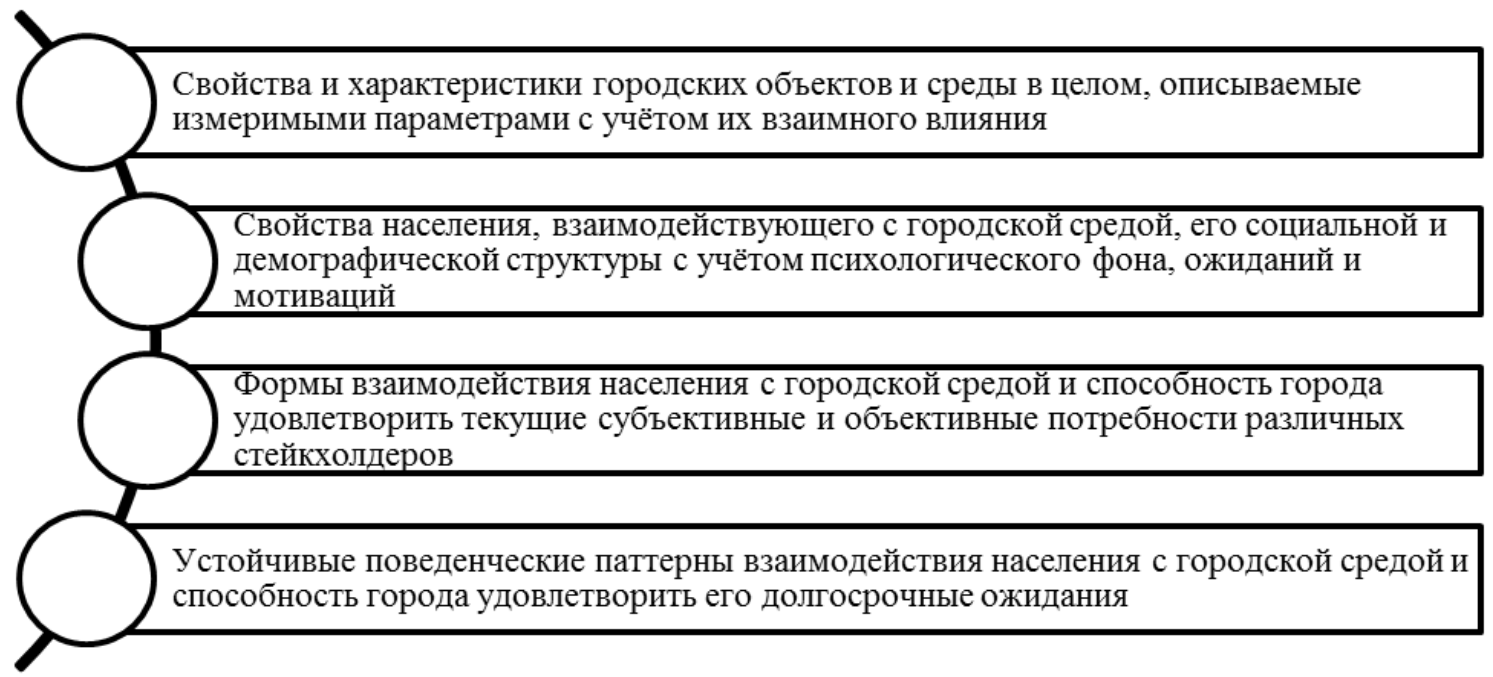

Рис. 2 - Особенности умного города

Проектирование умного города - сложный многофункциональный процесс, требующий огромных усилий и значительных затрат времени. При формировании такого рода проекта важно в полном объёме учитывать отраслевую структуру инфраструктуры, её развитость и качественное состояние, а также охватывать наибольшее число фракторов городской среды, оказывающих влияние на модель взаимодействия человека с городом.

\section{Санкт-Петербурга}

Реализация концепции умного города применительно к мегаполису: пример

Рассматривая возможность реализации концепции "умного города" на примере такого мегаполиса как Санкт-Петербург, необходимо учитывать уровень развития инфраструктуры города в настоящий момент, чтобы определить наиболее гибкий и планомерный подход к внедрению основных элементов стратегии. Целесообразно выделить несколько этапов реализации проекта "умный город", представленных в форме Рис. 3.

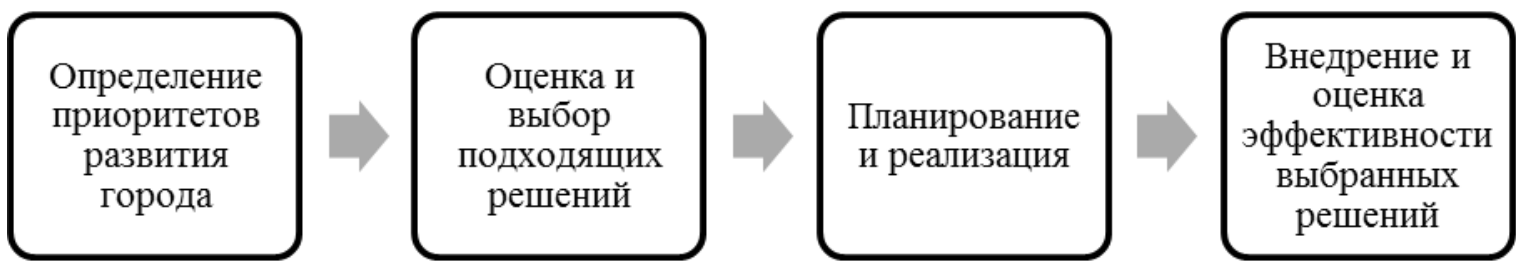

Рис. 3 - Этапы реализации концепции "умный город"

Исходя из того, что главной целью реализации стратегии умного города является обеспечение комфортных условий для проживания, можем выделить опорную исходную задачу, которая будет являться стимулом для Санкт-Петербурга - это обеспечение высокого качества жизни населения посредством рационально развитой инфраструктуры, эффективной обратной связи между органами управления и гражданами, повышения уровня экологической и техногенной безопасности [23], [24], [25], [26], [27]. Для реализации данной задачи необходима устойчивая технологическая база, включающая современные ИКТ и резервы их бесперебойной работы (IT-кадры, энергетические ресурсы). Кроме того, основой успешной модернизации любого города является экономическая си- 
ла в лице действующих предпринимателей и бизнес-компаний. В данном случае, учитывая цифровой характер преобразований, особое значение имеют ІТ-компании. Программы социально-экономического развития города Санкт-Петербург содержат элементы поддержки данных хозяйствующих субъектов экономики. В связи с этим в рамках системы "умного города" перед Санкт-Петербургом вырисовывается дополнительная задача, связанная с организацией единого информационного бизнес-пространства.

Каждая задача, реализуемая в рамках стратегии "умного города", отталкивается от определённой производственной или непроизводственной сферы города [28]. В зависимости от её структуры и функциональных особенностей, стратегия внедрения концепции "умный город" требует определённого рода адаптаций и индивидуальных решений.

Выделим основные сферы, требующие комплексного технологического подхода:

1. Сфера здравоохранения. Использование ИКТ для оперативного обмена медицинской информацией (телемедицина), в частности технологий Big Data для составления умных медицинских карт с возможностью точного диагностирования и прогнозирования заболеваний; оценка качества обслуживания пациентов и умный рейтинг здравоохранительных учреждений.

2. Сфера социального обеспечения. Разработка своего рода единой карты или бейджа горожанина, отражающих исчерпывающую информацию о нём, роде его занятий и профессиональной деятельности для предоставления социальных гарантий и возможности осуществлять фиинансовые операции.

3. Сфера градостроительства. Планирование развития территорий города с помощью ВІМ-технологий; формирование цифрового облика городской инфраструктуры; комплексная оценка проектов по постройке/реставрации/реновации архитектурных объектов; организация сквозной городской сети пешеходных и зелёных зон, адаптированных для передвижения лиц с ограниченными возможностями.

4. Сфера экологии. Применение ИКТ для онлайн-мониторинга состояния атмосферного воздуха и воды; организация раздельного сбора и переработки твёрдых отходов.

5. Cфера транспорта. Гибкая транспортная сеть; "умные" светофоры, минимизация автомобильных пробок на основе систем мобильности (каршеринг [29], инновационные модели общественного транспорта).

6. Сфера телекоммуникаций. Установка телекоммуникационных вышек, обеспечивающих повсеместное покрытие сетью 5G; интеграция сенсорных датчиков в объекты управления для реализации технологии интернета вещей; единое информационное пространство.

Bce вышеизложенные сфреры в совокупности с информационнокоммуникационными технологиями направлены на создание мощной экосистемы умного города.

\section{Оценка рисков и преимуществ умной трансформации}

Концепция "умного города" с течением времени набирает всё большую популярность. Умные города имеют ряд преимуществ, главным из которых является обеспечение комфортных условий для развития каждого отдельного человека. Однако, для реализации проекта "умного города" следует также учитывать риски, которые могут внести свои коррективы в достижение поставленных целей [30]. Основные преимущества и риски, выявленные по результатам проведённого исследования, представлены в Таблице.

Как показывает отечественная и мировая практика, умный город проще построить "с нуля", так как модернизация устоявшейся городской инфраструктуры - сложный многоступенчатый процесс, требующий колоссальных реформ и огромных сумм денежных вложений. Тем не менее, некоторые крупные мегаполисы, такие как Сингапур, Копенгаген, Барселона, Амстердам и другие успешно внедряют смарт-технологии в городскую инфраструктуру. К примеру, в Сингапуре усовершенствована транспортная система посредством использования датчиков плотности транспортного потока, смарт-парковок и смарт-светофоров, а Барселона благодаря применению интеллектуальных систем решила проблемы с расходом воды и загрязнением воздуха [31]. 
Таблица - Соотношение преимуществ и рисков умной трансформации города

\begin{tabular}{|c|c|}
\hline Преимущества & Риски \\
\hline $\begin{array}{l}\text { • } \\
\text { городскими процессами } \\
\text { • } \quad \text { Обеспечение порядка и без- } \\
\text { опасности в городе } \\
\text { • } \quad \text { Эфрфективные управленче- } \\
\text { ские решения по развитию города } \\
\text { • } \\
\text { зования городской инфраструктуры }\end{array}$ & $\begin{array}{l}\text { • } \\
\text { проекта } \\
\text { • } \quad \text { Сложность реализации, требующая } \\
\text { высококвалифицированного кадрового по- } \\
\text { тенциала в сфрере IT } \\
\text { • } \quad \text { Риски цифрового контроля над пове- } \\
\text { дением населения } \\
\text { • } \quad \text { Дискомфорт для граждан, вынужден- } \\
\text { ных переходить на новую модель функцио- } \\
\text { нирования города } \\
\text { • } \quad \text { Несанкционированное использова- } \\
\text { ние информации о гражданах, кража данных }\end{array}$ \\
\hline
\end{tabular}

\section{Заключение}

Переход к фуннционированию российских городов в фрормате "умного города" способен повысить качество жизни населения и эффрективность управления городскими процессами. Кроме того, поскольку "умный город" представляет собой цифровую трансформацию модели организации взаимодействия и функционирования стейкхолдеров в городе, внедрение этой концепции является насущной необходимостью. Цифровая трансформация охватывает все сферы жизни общества, и город как основное сосредоточение социальной, экономической и политической активности не может остаться в стороне.

Проект "умный город" требует значительных инвестиционных вложений как в производство ИКТ и цифровых технологий, так и в профессиональную подготовку специалистов в сфрере IT, а также согласования с жителями города с целью учёта их мнения о разрешении на обработку собираемых данных. Это означает, что процесс создания "умного города" должен быть максимально прозрачным для населения, чтобы обеспечить учёт его интересов, а самому внедрению должна предшествовать тщательная организационная и технологическая подготовка, а также социально-психологическая работа с населением.

\section{Благодарности}

Исследование выполнено при финансовой поддержке РФФИ в рамках научного проекта № 20-010-00942 А.

\section{Список использованных источников}

1. Князьнеделин Р.А., Бекмурзаев И.Д., Титов В.А. Повышение эфффективности системы государственных закупок на основе цифровых платформ // Вестник Тверского государственного университета. Серия: Экономика и управление. - 2019. - № 2. - С. 5361.

2. Артёмова А.И., Нурмухаметов Р.К. Концепция "умный город": сущность и содержание // Вестник Тульского филиала Финуниверситета. - 2019. - № 1-1. - С. 53-61.

3. Катрашова Ю.В., Митяшин Г.Ю. Преимущества и угрозы внедрения технологии больших данных в систему государственного управления // Актуальные проблемы аграрной науки: прикладные и исследовательские аспекты. Сборник научных трудов Всероссийской (национальной) научно-практической конференции. - Нальчик, 2021. - С. 367 370.

4. Милькина И.В., Косарин С.П. Искусственный интеллект в системе управления городом // Шаг в будущее: искусственный интеллект и цифровая экономика. Материалы 1-й Международной научно-практической конференции / Государственный университет управления. - М., 2017. - С. 258-264.

5. Подгайская А.Э. Факторы успеха каршеринг-сервисов в России // Регион: Экономика и Социология. - 2019. - № 2(102). - С. 270-289.

6. Травуш В.И. Цифровые технологии в строительстве // Academia. Архитектура и строительство. - 2018. - № 3. - С. 107-117. 
7. Комарова И.П., Сигарев А.В., Устюжанина Е.В. Дистанционная занятость в формируемой в России цифровой экономике: уроки пандемии // Российский экономический журнал. - 2020. - № 4. - С. 31-41.

8. Котляров И.Д. Нестандартные фрормы занятости // Общество и экономика. 2015. - № 1-2. - С. 203-218.

9. Курбанов А.Х., Плотников В.А. Оценка перспектив развития логистики в условиях цифровизации экономики и трансформации социальной сферы // Известия СанктПетербургского государственного экономического университета. - 2020. - № 3(123). - С. 94-101.

10. Плещенко В.И. Логистическая деятельность под ударом эпидемии коронавируса: реальность и перспективы // Логистика сегодня. - 2020. - № 4. - С. 254-259.

11. Василенко И.А. "Умный город" как социально-политический проект: возможности и риски смарт-технологий в городском ребрендинге // Власть. - 2018. - Т. 26. - № 3. - С. 13-19.

12. Камолов С.Г., Корнеева А.М. Технологии будущего для "умных городов" // Вестник Московского государственного областного университета. Серия: Экономика. 2018. - № 2. - С. 100-114.

13. Куприяновский В.П., Акимов А.В., Покусаев О.Н., Аленьков В.В., Намиот Д.Е., Синягов С.А. Интеллектуальная мобильность и мобильность как услуга в умных городах // International Journal of Open Information Technologies. - 2017. - T. 5. - № 12. - C. 77-122.

14. Ганченко Д.Н., Тарзанова Ю.А. Комфортная городская среда: инновация или трансформация термина // Развитие теории и практики управления социальными и экономическими системами. Материалы Восьмой международной научно-практической конференции. - Петропавловск-Камчатский, 2019. - С. 81-85.

15. Пролубников А.В. Платформенная модель государственной экономической политики // Многоуровневое общественное воспроизводство: вопросы теории и практики. - 2020. - № 18(34). - С. 21-33.

16. Плотников В.А. Цифровизация как закономерный этап эволюции экономической системы // Экономическое возрождение России. - 2020. - № 2(64). - С. 104-115.

17. Ganchenko D.N., Bodrov A.A. Digitalization of housing and communal services in the context of new industrialization // Proceedings of the 1st International Scientific Conference "Modern Management Trends and the Digital Economy: from Regional Development to Global Economic Growth" (MTDE 2019). Cep. "Advances in Economics, Business and Management Research". - 2019. - C. 192-197.

18. Попов Е.В., Семячков К.А. Семь приоритетов развития "умных" городов // Национальные интересы: приоритеты и безопасность. - 2020. - Т. 16. - № 2(383). - С. 200-216.

19. Бекмурзаев И.Д., Курбанов А.Х., Курбанов Т.Х. Направления и этапы построения логистических систем на основе использования цифровых технологий // Экономические и социально-гуманитарные исследования. - 2018. - № 4(20). - С. 5-9.

20. Кощеев В.А., Цветков Ю.А., Вишнивецкая А.И. Элементы цифровой экономики в жилищно-коммунальном хозяйстве // Вестник гражданских инженеров. - 2019. - № 2(73). - С. 173-179.

21. Мингалева Ж.А. Применение концепции "умных" городов для решения проблем урбанистики // Инновационное развитие экономики: тенденции и перспективы. 2015. - T. 1. - C. 87-94.

22. Пахомов Е.В. Технологическая основа умного города // Инженерный вестник Дона. - 2017. - № 3(46). - С. 72.

23. Енин А.Е., Витковская А.С. Концепция "умный город" как подход к городскому развитию // Архитектурные исследования. - 2018. - № 2(14). - С. 78-86.

24. Капранова Л.Д. Цифровая экономика в России: состояние и перспективы развития // Экономика. Налоги. Право. - 2018. - Т. 11. - № 2. - С. 58-69.

25. Магомедов Р.М., Иванов А.И. Структура электронного правительства в Российской Федерации // Самоуправление. - 2020. - Т. 2. - № 2(119). - С. 316-319.

26. Устюжанина Е.В., Сигарев А.В., Шеин Р.А. Цифровая экономика как новая парадигма экономического развития // Экономический анализ: теория и практика. - 2017. № 12(471). - С. 2238-2253.

27. Макаров В.Л., Бахтизин А.Р., Бекларян Г.Л., Акопов А.С. Имитационное моделирование системы "умный город": концепция, методы и примеры // Национальные интересы: приоритеты и безопасность. - 2019. - Т. 15. - № 2(371). - С. 200-224. 
28. Митягин С., Васильев В. Умный Санкт-Петербург: комплексный подход к внедрению информационных технологий управления мегаполисом. - Control Engineering Россия. - 2019. - № 1(79). - С. 18-25.

29. Котляров И.Д. Организация автотранспортного обслуживания на основе коммерческого каршеринга // Мир транспорта. - 2016. - Т. 14. - № 6(67). - С. 78-85.

30. Попов Е.В., Семячков К.А. Систематизация подходов к оценке развития умных городов // Экономика региона. - 2020. - Т. 16. - № 1. - С. 14-27.

31. Филин Е.И., Родина Т.Е. Технологии "умных" городов и прогнозы их развития // Вызовы цифровой экономики: условия, ключевые институты, инфраструктура. Сборник статей I Всероссийской научно-практической конференции. - Брянск, 2018. - С. 103-105. 